\title{
EFL Students' Perceptions of Collaborative Writing in a Private University, Vietnam
}

\author{
Ly Minh Trinh ${ }^{1}$, Huan Buu Nguyen ${ }^{2}$ \\ ${ }^{1}$ Mekong University, Vietnam \\ ${ }^{2}$ Can Tho University, Vietnam
}

\begin{abstract}
Writing is widely held as the most important but sophisticated skill in learning foreign languages, including English. In particular, in college writing, students need to acquire and improve their writing performance in order to communicate ideas to intended audience or academia. Thus, as a communicative activity, writing cannot be done in isolation. Instead, collaborative writing has been advocated as a socially constructed activity done by more individuals to produce a particular text. However, individual writing still dominates in the writing context in Vietnam, thereby deterring students from writing collaboratively with others. This paper therefore seeks the students' perceptions about collaborative writing. Data collected for this study include questionnaire and interviews. Participants were 147 students of English at a university in the Mekong Delta, Vietnam. The findings indicate that students had positive perceptions about collaborative writing. Implications for collaborative writing are also provided.
\end{abstract}

Keywords: collaborative writing, perceptions, communicative activity, writing

\section{Introduction}

Collaborative writing has taken its place in providing students with an opportunity to better their writing and language use and through working together to produce a given assignment (McDonough, Vleeschauwer, \& Crawford, 2019; Storch, 2005, 2013). These studies into this area have shown potential benefits of promoting students' learning process for a quality written project with particular regard to content, vocabulary, and accuracy(Anggraini, Rozimela, \& Anwar, 2020). This productive skill allows students to become proficient in using the target language, namely English and optimize their writing products, thereby influencing how students communicate their ideas to academic audiences or peers in clear and meaningful ways and facilitate their English language learning. However, teaching writing in English within the Vietnamese context is challenged by exam-focused mode and students lack confidence in working with other peers to complete a written text in a conventional learning environment (Tran, 2019). This may be due to limited time of practice, conflicting opinions, and mixed-level of English language proficiency, and students' attitudes towards working or writing in collaboration with others. Understanding such pressure is put on students to change their ways of learning to write, examining how collaborative writing influences students to learn writing in English as a foreign language in a tertiary context is necessary. In Vietnam, few studies have been conducted to investigate the effects and students' perceptions of collaborative writing. This paper therefore examines students' perceptions of collaborative writing at a private university in the Mekong Delta, Vietnam. The research question that guided the study was, "What are students' perceptions of the effects of collaborative writing in English as a foreign language (EFL) classrooms?"

\section{Collaborative writing}

There are several definitions of collaborative writing in the literature. Collaborative writing is viewed as a writing jointly produced by two or more students (Howard, 2001). From the socio cultural perspective (Vygotsky, 1978), collaborative writing necessitates students to take responsibility for their own learning through interaction and participation while completing a given writing task. In this interactional and communicative process, this productive learning allows students greater opportunities to discuss, organize, edit, and refine their writing complexities.

Research has indicated the varying degrees of the effects and students' perceptions of collaborative writing in their learning process. These positive sides are evidenced in Malaysia (Fung, 2006), the United States (Bikowski \& Vithanage, 2016), Indonesia (Anggraini et al., 2020), in China (Zhang, 2018), Saudi Arabia (Alawaji, 2020), in Spain (Dobao \& Blum, 2013; Villarreal \& Gil-Sarratea, 2020), and in Vietnam(Pham, 2021). In other words, the findings from these studies reveal that collaborative writing is a useful strategy that offers students the opportunity to pool ideas, improve writing quality regarding content, organization, and vocabulary. 
In a classroom-based study on three case study groups with nine undergraduates on the nature of collaborative writing in a Malaysian tertiary setting, Fung (2006)reported that collaboration is influenced by group writing, role flexibility, and task complexity. Interactions, shared expertise, and creative use of language were identified as common features of collaborative process with regard to knowledge construction and language use.

In a research conducted with fifty-two L2 writers from a writing class in the United States university, Bikowski and Vithanage (2016) indicated that collaborative writing could improve students' writing quality.

In Anggraini and his colleagues'(2020) study of the effects of collaborative writing on EFL learners' writing skills and their perceptions of the strategy in Indonesia, the result of the study revealed that collaborative writing could assist students in generating ideas and activating their prior knowledge of a given topic and that this strategy addressed students' positive perceptions about this writing strategy.

In a study conducted with thirty-five pairs of Chinese EFL learners to write argumentative essays in English, the co-constructed essays were rated for complexity, accuracy, fluency and text quality. Zhang(2018) revealed that collaboration led to higher syntactic complexity but no differences in accuracy, fluency, and text quality.

In a study by Alawaji (2020) on students' perceptions of collaborative summary writing in Saudi Arabia, this author indicated that most participants held positive attitudes toward collaborative writing and found this strategy useful in building up students' confidence, writing skills, and language proficiency.

A study conducted with thirty-two students in an EFL setting on the effect of collaborative writing in Spain by Villarreal and Gil-Sarratea(2020) revealed that collaboration provided students with an opportunity to generate ideas, use the target language, and give feedback to other peers. Moreover, this productive strategy was observed to be useful for improving the content, structure, organization of ideas, except complexity and fluency.

A more recent study by Pham was conducted to examine the effects of collaborative writing on students' writing fluency in a university in Vietnam. This study indicated that collaborative writing not only positively influenced students' writing fluency but also yielded their positive attitudes.

These studies above suggest that, despite its potential effects of collaborative writing in a variety of school contexts, this collaborative strategy has not been researched at tertiary levels for English-majored students in a private university. Thus, the study discussed in this paper contributes to the literature on collaborative writing in EFL contexts.

\section{The study}

This study used quantitative and qualitative approaches to collect the data. The quantitative approach involves a collection of information of a particular study using statistical analysis(Creswell, 2014). The qualitative approach, on the other hand, allows participants to obtain detailed and rich information about the results of a given study through their views and experiences(Fraenkel, Wallen, \& Hyun, 2012).

The questionnaire adapted from Abahussain (2020)was used to collect quantitative data. The first section includes the items about the personal information of the participants as age, gender, number of years of learning English at current university. The second section (items 1-6) include the items about participants' understanding of the concept of collaborative writing. The third section (items 7-28) is related to participants' perceptions of the effects of collaborative writing. In particular, there are four sub-categories: statements with regard to students' opinions about the social interaction when writing collaboratively (items $7,8,9,10,11,12$ ), students' opinions about motivation when learning how to write collaboratively (items 13, 14, 15, 16, 17), students' opinions about language development while writing collaboratively with peers (items 18, 19, 20, 21), and students' opinions about challenges they encounter while writing with their peers (items 22, 21, 22, 23, 24, 25, $26,27,28)$. The students were asked to express how much they agreed or disagreed with the statements through 5-point Liker-scale. Semi-structured interviews were used to gain insights into participants' perceptions of collaborative writing and the challenges they have. The interview questions were based the questionnaire items, namely students' understanding about collaborative writing, students' opinions about collaboration in writing, 
DOI: $10.51386 / 25815946 /$ ijsms-v4i3p117

Volume: 4 Issue: 3

May to June 2021

www.ijsmsjournal.org

and students' perceptions of the challenges in collaborative writing.147 students (41 males and 106 females) of English majors at a private university were invited to answer the questionnaires. Their age ranges from 18 to 24 years old and they have different years in learning English.

To ensure the validity and ease of use of the questionnaire, it was first translated into Vietnamese and then proofread by two teachers of English who had experience in doing research. Then, some questionnaire items were changed to ensure the clarity and understanding of the items delivered to the respondents. The questionnaire was then piloted to 23 students in the first week of the study. The purpose of the pilot was to obtain the feasibility of the main study and appropriate use of the instrument (Cohen, Manion, \& Morrison, 2011; Fraser, Fahlman, Arscott, \& Guillot, 2018). The scale test was employed to check the reliability of the pilot questionnaire. The overall Cronbach's reliability coefficient $(\alpha)$ was 0.8 , indicating that the questionnaire was confirmed to bea reliable instrument for use in the main study. Quantitative data were analyzed by using SPSS version 20. The qualitative data was collected by semi-structured interviews to get insights into students' perceptions of the effects of collaborative writing on their writing performance. All interviews were hand-coded, transcribed, and then transcribed from Vietnamese into English. All of the interview transcripts were read and checked carefully and then categorized into themes to answer the above-mentioned research question.

\section{Findings}

This section presents the findings to the research question about students' perceptions of the effects of collaborative writing on their writing performance in a private university in the Mekong Delta, Vietnam. The findings indicate that most of the participating students expressed their conceptual understanding at a high level and were positive about collaborative writing in writing practices, as illustrated in the following sections.

\subsection{Insights into students' understanding of collaborative writing}

Section Two of the questionnaire includes six items (items 1-6) designed to measure students' understanding of collaborative writing, as shown in Table 1.

Students' understanding of collaborative writing

Table 1Students' understanding of collaborative writing (CW)

\begin{tabular}{|c|c|c|c|c|c|c|}
\hline & Items & $\mathbf{n}$ & Min & Max & $\mathbf{M}$ & SD \\
\hline 1 & $\mathrm{CW}$ is based on the student-centered approach & 147 & 2 & 5 & 4.07 & 0.69 \\
\hline 2 & CW involves communicative activities. & 147 & 1 & 5 & 4.00 & 0.85 \\
\hline 3 & CW is a separate work from each member in a group. & 147 & 1 & 5 & 2.55 & 1.35 \\
\hline 4 & $\mathrm{CW}$ is a written activity by two or more people & 147 & 1 & 5 & 4.22 & 0.75 \\
\hline 5 & $\begin{array}{l}\text { CW refers to improvements in other skills of students' English } \\
\text { language learning (listening, speaking, reading). }\end{array}$ & 147 & 1 & 5 & 4.19 & 0.85 \\
\hline 6 & $\begin{array}{l}\mathrm{CW} \text { is related to activities that group members participate in } \\
\text { processing information. }\end{array}$ & 147 & 1 & 5 & 4.21 & 0.73 \\
\hline
\end{tabular}

Table 1 shows that the overall mean scores of collaborative writing, except item $3(M=2.55, S D=1.35)$, is at the high level. In other words, students conceptualized the meaning of collaborative writing in their learning process. In particular, students agreed with the idea that collaborative writing involves the jointly written work of several people (item 4$)$ and this accounted for the highest scores $(M=4.22, S D=.75)$, followed by item 6 with regard to the activities group members participate in information processing $(M=4.21, S D=.73)$. The mean score of Item 5 indicating that collaborative writing as the improvements in other skills in English, was reported by students much higher as compared to other items $(M=4.19, S D=.85)$. Regarding item 1 , students believed that collaborative writing is grounded on the role of students in their writing practices $(M=4.07, S D=.69)$. Students also reported their understanding of the value of collaborative writing as communicative-based (item 2) was at high level $(M=4.00, S D=.85)$.However, few students agreed with the idea that collaborative writing was individual work that is done separately (item 3$)(M=2.55, S D=1.36)$. In other words, this finding indicates that students did not know or understand the concept of collaborative writing while working with other peers.

Students' perceptions of collaborative writing $(C W)$ 
Section Three consists of 15 items (items 7-21), as illustrated in Table 2. Table 2 shows the mean scores of the three subcategories of collaborative writing (social interaction, self-confidence, and linguistic development).

\begin{tabular}{|c|c|c|c|c|c|c|}
\hline & Social interaction & $\mathbf{n}$ & Min & Max & M & SD \\
\hline 7 & $\mathrm{CW}$ is fun with group members while working together. & 147 & 1 & 5 & 3.89 & .91 \\
\hline 8 & CW allows individuals to listen and share opinions or views. & 147 & 1 & 5 & 3.94 & .82 \\
\hline 9 & $\begin{array}{l}\text { CW allows individuals to write all parts of the assignment instead } \\
\text { of splitting them }\end{array}$ & 147 & 1 & 5 & 3.48 & 1.19 \\
\hline 10 & $\begin{array}{l}\mathrm{CW} \text { is time-consuming in spell check, punctuation, grammar } \\
\text { compared to individual work. }\end{array}$ & 147 & 1 & 5 & 3.99 & .87 \\
\hline 11 & CW allows each group member equal shared writing. & 147 & 1 & 5 & 3.74 & 1.08 \\
\hline 12 & $\mathrm{CW}$ involves group members to discuss the content together. & 147 & 1 & 5 & 3.97 & .69 \\
\hline \multicolumn{7}{|c|}{ Self-confidence } \\
\hline 13 & I have the opportunity to share my views in the group. & 147 & 1 & 5 & 4.03 & .83 \\
\hline 14 & I feel that my ideas are considered while writing with others. & 147 & 1 & 5 & 3.98 & .81 \\
\hline 15 & I feel comfortable to give or share ideas with others. & 147 & 1 & 5 & 3.70 & .98 \\
\hline 16 & I like to collaborate with others to complete a writing assignment. & 147 & 1 & 5 & 3.82 & .96 \\
\hline 17 & I learn a lot from group writing activity rather doing it alone. & 147 & 1 & 5 & 4.07 & .86 \\
\hline \multicolumn{7}{|c|}{ Linguistic development } \\
\hline 18 & I think collaborative writing helps me improve grammar. & 147 & 1 & 5 & 4.01 & .81 \\
\hline 19 & I think collaborative writing helps me organize the structure well. & 147 & 1 & 5 & 4.10 & .81 \\
\hline 20 & I think collaborative writing helps me improve the contents. & 147 & 1 & 5 & 3.97 & .86 \\
\hline 21 & I think collaborative writing helps me improve vocabulary. & 147 & 1 & 5 & 4.05 & .87 \\
\hline
\end{tabular}

Table 3 below shows the results of the Descriptive Statistics test with regard to the overall mean score of students' perceptions of collaborative writing and those of the three sub-categories of collaborative writing. The terms SI, SC, and LD stand for social interaction, self-confidence, and linguistic development respectively.

Table 3 Descriptive statistics of students' perceptions of $\mathrm{CW}$

\begin{tabular}{llcc}
\hline Category & N & M & SD \\
\hline MeanOverall & 147 & 3.51 & .38 \\
MeanSI & 147 & 3.83 & .64 \\
MeanSC & 147 & 3.92 & .62 \\
MeanLD & 147 & 4.03 & .67 \\
\hline
\end{tabular}

The results of the test reveal that the overall mean score of students' perceptions of collaborative writing is at a high level $(M=$ $3.51, S D=.38)$. Of the three subcategories of collaborative writing, the mean score of linguistic development is the highest $(M=4.03, S D=.67)$, followed by self-confidence $(M=3.92, S D=.62)$, and social interaction $(M=$ 3.83, $S D=.64)$.

A Paired Sample t- Test was computed to determine whether there is a significant difference between the mean scores of each pair from three subcategories in relation to students' collaborative writing, as illustrated in Table 4. The three pairs are identified as Pair 1 (social interaction-self-confidence); Pair 2 (social interactionlinguistic development), Pair 3 (self-confidence- linguistic development).

Table 4 Results of Paired Sample t-Tests

\begin{tabular}{llll} 
& & $\mathbf{t}$ & $\mathbf{p}$ \\
\hline Pair 1 & MeanSI - MeanSC & -1.992 & 0.048 \\
\hline Pair 2 & MeanSI - MeanLD & -4.522 & 0.000 \\
\hline Pair 3 & MeanSC - MeanLing & -2.220 & 0.028 \\
\hline
\end{tabular}

As can be seen from Table 4, there was a statistically significant difference between the mean score of social interaction and self-confidence $(t=-1.992, p=.048)$. The mean score of self-confidence was higher than that of social interaction $(M S C=3.92, S D=.62 ; M S I=3.83, S D=.64)$. In other words, students perceived selfconfident enhancement as higher compared to social interaction improvement. As can be seen from Table 4.3, 
there were statistically significant differences between the mean scores on social interaction and linguistic development $(t=-4.522, p=.000)$. This result reveals that students perceived linguistic development as higher compared to social interaction $(M L D=4.03, S D=.67 ; M S I=3.83, S D=.64)$, respectively. Similarly, to assess which aspects helped students improve when writing collaboratively with their peers: self-confidence or linguistic development, Paired Sample t-Test was conducted. The result indicates that there was a statistically significant difference between the mean score of self-confidence and that of linguistic development $(t=-2.220$, $p=.028)$. The mean score of linguistic development is higher than that of self-confidence $(M L D=4.03, S D=.67$; $M S C=3.92, S D=.62)$, respectively. In other words, students perceived linguistic development as higher compared to self-confidence about collaborative writing.

\section{Finding from the interviews}

The purposes of the interviews were to gain insights into students' perceptions of the effects of collaborative writing and their understanding about collaborative writing.

\section{Insights into understanding of collaborative writing}

Analysis from the interview data reveals that all of the interviewees thought that collaborative writing was the writing task that involves many people in completing a given assignment. The following excerpts illustrate their views.

Collaborative writing is viewed as a group of students who work together to discuss a topic through brainstorming ideas and starting to write a given assignment (Student 1, interview extract)

Collaborative writing is an activity in which people in a group worked together. The group can arrange the time, discuss over this activity, give ideas or opinions and put these ideas together before completing the writing product (Student 5, interview extract)

The above quote suggests that the students conceptualized collaborative writing as a interactive process that joins two or more peers to share understanding and knowledge to complete a writing assignment. In particular, the students reported that collaborative writing is a group activity that allows for brainstorming, discussing, and generating ideas.

\section{Students' perceptions of collaborative writing}

When asked what students' perceptions of collaborative writing mean, most of the interviewed students revealed that they perceived collaborative writing as useful in several ways. These are identified as more ideas, vocabulary, and good grammar. The following excerpts illustrate their views.

\section{Generating ideas from joint activity}

While working with friends over a writing activity, we come up with many ideas. If I did not know anything, my friends would explain them to me. Thus, the writing assignment was completed with a variety of opinions from different people and in fact, the group work in writing would be better than my individual assignment. (Student 1, interview extract)

In working with other friends to complete a given writing assignment, there are more ideas generated from each student. For example, when writing a plan to start up a flower shop, I can write by myself. However, after discussing with group members, the final product consists of more ideas (Student 5, interview extract)

I feel that if I work alone, I have my shortcomings and fewer ideas, but... When working in groups, my friends will help me develop more ideas. (Student 10, interview extract)

Vocabulary enhancement 
[...] I feel my vocabulary has improved a lot. [...] I often have errors in repeating words in writing. While writing in group, I asked other friends if there were other words to substitute, and then my friend would suggest some synonyms (Student 2, interview extract)

My writing skills improve in many ways [...] from what we discuss ideas and consider what would be the answer for the final version, I learned that exposure to new words shared or generated by my friends could build up my vocabulary list (Student 10 , interview extract).

\section{Improvement in grammar}

Most of the students claimed that their grammar knowledge could be improved. The two extracts below illustrate their views.

When I write something incorrect, my friends help me correct these grammatical mistakes. Also, I feel confident when working in group (Student 1, interview extract)

I learn a lot when writing collaboratively. In fact, I know how to organize ideas, use correct structures to complete the task.

\section{Discussion \\ The findings of the study indicate that the participating students had positive perceptions of collaborative writing in their learning process as a result of better understanding of this learning strategy. The following section discusses the findings of the study to answer the research question. \\ Research Question: What are students' perceptions of the effects of collaborative writing on their writing performance at a private university?}

The findings from the study indicate that participating students conceptualized the meaning of collaborative writing at a high level and that they perceived collaborative writing as useful to complete a given writing text. The study confirms the findings from several studies in the literature (Abahussain, 2020; Bikowski \& Vithanage, 2016; Dobao \& Blum, 2013; Storch, 2013). These authors indicate that collaborative writing provides students with an opportunity to enhance their writing ability or performance and other skills in English. Analysis from the interview data of the study reveal that students acknowledged collaboration and interaction could forward their thinking for ideas, vocabulary, grammar, and sense of confidence with others, in pairs or groups. In addition, students reported that collaborative writing could allow them to feel that they could have more ideas, share information, and that their grammatical and lexical accuracy of English use in a given text were likely to increase. This finding fits well with studies by Storch (2005), Dobao and Blum (2013) who claim that collaborative writing is anapposite writing strategy that students could glean ideas, improve the quality of a specific text regarding content, language use, and vocabulary.

\section{Conclusions}

The findings add to the literature on collaborative writing that fosters students' writing performance in EFL contexts, particularly in a private university in the Mekong Delta, Vietnam. As participating students perceived the potential effects of collaborative writing from teaming up with peers, there are some implications for teachers and students. First, teachers should consider when and how to provide students with learning opportunities to improve English language use through collaborative writing activities or tasks in their teaching practices in writing classes. The findings from the study may raise students' awareness of the value of collaboration and interaction in improving their writing quality and own styles in relation to other English language skills while constructing new and meaningful knowledge to communicate ideas to others.

\section{About the authors}

Ly Minh Trinh is a lecturer in English at Mekong University, Vietnam. Sheis a master candidate in education, School of Foreign Languages, Can Tho University. Her research interests include teaching methodologies, listeningskills, and ESP.

Huan Buu Nguyen is an Associate Professor at Department of English Language and Culture, School of Foreign Languages, Can Tho University, Vietnam. His research interests include teacher change, ESP, and curriculum planning. He is now involved in writing teaching materials for students at the university. 


\section{References}

[1] Abahussain, M. O. (2020). Investigating EFL learners' perceptions of collaborative writing. International Journal of English Linguistics, 10(3), 32-47. doi: https://dx.doi.org/10.5539/ijel.v10n3p32

[2] Alawaji, N. N. M. (2020). Students' perceptions of collaborative summary writing. Theory and Practice in Language Studies, 10(6), 700-707. doi: https://dx.doi.org/10.17507/tpls.1006.11

[3] Anggraini, R., Rozimela, Y., \& Anwar, D. (2020). The effects of collaborative writing on EFL learners' writing skills and their perception of the strategy. Journal of Language Teaching and Research, 11(2), 335-341. doi: https://dx.doi.org/10.17507/j1tr.1102.25

[4] Bikowski, D., \& Vithanage, R. (2016). Effects of web-based collaborative writing on individual L2 writing development. Language Learning and Technology, 20(1), 79-99.

[5] Cohen, L., Manion, L., \& Morrison, K. (2011). Research methods in education (7th Ed.). Abingdon, Oxon; New York, NY: Routledge.

[6] Creswell, J. W. (2014). Research design: Qualitative, quantitative, and mixed methods approaches (4nd Ed.). Thousand Oaks, California: SAGE Publications.

[7] Dobao, A. F., \& Blum, A. (2013). Collaborative writing in pairs and small groups: Learners' attitudes and perceptions. System, 41(2), 365-378. doi: https://dx.doi.org/10.1016/j.system.2013.02.002

[8] Fraenkel, J. R., Wallen, N. E., \& Hyun, H. H. (2012). How to design and evaluate research in education (8th Ed.). New York: McGraw-Hill Humanities.

[9] Fraser, J., Fahlman, D. W., Arscott, J., \& Guillot, I. (2018). Pilot testing for feasibility in a study of student retention and attrition in online undergraduate programs. International Review of Research in Open and Distributed Learning, 19(1), $260-278$.

[10] Fung, Y. M. (2006). The nature and dynamics of collaborative writing in a Malaysian tertiary ESL setting. (PhD), Massey University, New Zealand.

[11] Howard, R. M. (2001). Collaborative pedagogy. In G. Tate, A. Rupiper \& K. Schick (Eds.), A guide to composition pedagogies (pp. 54-70). Oxford: Oxford University Press.

[12] McDonough, K., Vleeschauwer, J. D., \& Crawford, W. J. (2019). Exploring the benefits of collaborative writing in a Thai EFL context. Language Teaching Research, 23(6), 685-701. doi: https://dx.doi.org/10.1177/1362168818773525

[13] Pham, H. P. V. (2021). The effects of collaborative writing on students' writing fluency: An efficient framework for collaborative writing. SAGE Open, 11(1), 1-11. doi: https://dx.doi.org/10.1177/2158244021998363

[14] Storch, N. (2005). Collaborative writing: Product, process, and students' reflections. Journal of Second Language Writing, 14, 153173.

[15] Storch, N. (2013). Collaborative writing in L2 classrooms. Bristol: Multilingual Matters.

[16] Tran, L. C. T. (2019). Effects of collaborative writing on EFL learners' writing ability at high school. (Master), Tra Vinh University, Vietnam, Tra Vinh.

[17] Villarreal, I., \& Gil-Sarratea, N. (2020). The effect of collaborative writing in an EFL secondary setting. Language Teaching Research, 24(6), 874-897. doi: https://dx.doi.org/10.1177/1362168819829017

[18] Vygotsky, L. S. (1978). Mind in society. Cambridge, MA: Harvard University Press.

[19] Zhang, M. (2018). Collaborative writing in the EFL classroom: The effects of L1 and L2 use. System, 76, 1-12. doi: https://dx.doi.org/10.1016/j-system.2018.04.009 